\title{
Abstracts reporting of HIV/AIDS randomized controlled trials in general medicine and infectious diseases journals: completeness to date and improvement in the quality since CONSORT extension for abstracts
}

Jean Joel R. Bigna ${ }^{1 *}$, Jean Jacques N. Noubiap ${ }^{2,3}$, Serra Lem Asangbeh ${ }^{1}$, Lewis N. Um ${ }^{4}$ Paule Sandra D. Sime ${ }^{4}$, Elvis Temfack ${ }^{5,6}$ and Mathurin Cyrille Tejiokem ${ }^{1}$

\begin{abstract}
Background: Sufficiently detailed abstracts of randomized controlled trials (RCTs) are important, because readers often base their assessment of a trial solely on information in the abstract. We aimed at comparing reporting quality of RCTs in HIV/AIDS medicine before and after the publication of the 2008 CONSORT extension for abstracts and to investigate factors associated with better reporting quality.

Methods: We searched PubMed/Medline for HIV/AIDS RCTs published between 2006-07 (Pre-CONSORT) and 2014-15 (Post-CONSORT) in 40 leading general medicine and infectious diseases journals. Two investigators extracted data and scored abstracts. The primary outcome was the adjusted mean number of items reported among the 17 required. Proportions of abstracts reporting each of 17 items were considered as secondary outcome. The adjustment was done for journal field, CONSORT endorsement, abstract format, type of intervention, journal impact factor and authorship. This study received no funding.

Results: The adjusted mean number of reported items was 7.2 (95 \% Cl 6.6-7.7) in pre-CONSORT $(n=159)$ and 7.8 (95\% confidence interval [Cl] 7.3-8.4) in post-CONSORT ( $n=153$ ) (mean difference 0.7; $95 \% \mathrm{Cl} 0.1-1.2$ ). Journal high impact factor (adjusted incidence rate ratio 2.16; $95 \%$ Cl 1.83-2.54), abstract with 13 authors or more (1.39; $95 \% \mathrm{Cl} 1$. 07-1.79) and non-pharmacological intervention (1.19; $95 \% \mathrm{Cl}$ 1.03-1.37) were independent factors for better reporting quality. There were significant improvements in reporting on participants, randomization, outcome results, registration and funding; regression for author contact; and no change for other items: title, design, interventions, objective, primary outcome, blinding, number randomized, recruitment, number analyzed, harms and conclusions.
\end{abstract}

Conclusions: After the publication of the CONSORT extension for abstracts, the reporting quality of HIV/AIDS RCT abstracts in general medicine and infectious diseases journals has suboptimally improved. Thus, stricter adherence to the CONSORT for abstract are needed to improve the reporting quality of HIV/AIDS RCT abstracts.

Keywords: Abstract, Randomized controlled trial, CONSORT, HIV, AIDS, Systematic review

\footnotetext{
* Correspondence: bignarimij@yahoo.fr

${ }^{1}$ Department of Epidemiology and Public Health, Centre Pasteur of

Cameroon, Member of the International Network of the Pasteur Institute,

Yaoundé, Cameroon

Full list of author information is available at the end of the article
} 


\section{Background}

Randomized controlled trials (RCTs) which are designed to provide the best quality of evidence required for health care decisions $[1,2]$ should ideally be reported according to pre-defined standards. Most readers of articles reporting RCT usually start by making an initial assessment of the interest of the article after reading the content of the abstract, which subsequently guides the decision on whether to read the entire article or not [3]. With an overwhelming day-to-day workload, the continuous availability of large volumes of new scientific publications, limited access to many full-text articles (particularly in resource limited settings) [4], many health professionals tend to make recourse to information on abstracts to take health care decisions [3]. As such abstracts of trials reported in journals should contain sufficiently accurate and clear information that permits the reader to get a good synopsis of the findings of the trial [5]. Formerly, there was no standardized method of reporting RCT and this created many discordances in the reporting of RCTs. These discrepancies, stimulated the establishment of the Consolidated Standards of Reporting Trials (CONSORT) statement, the first of which was published in 1996 and revised in 2001 [6, 7], which aimed at "standardizing" and improving the way RCTs are reported [8]. In order to avoid inconsistencies between the content of the abstract and the full text of the article, as was seen in many RCT reports, an extension to the CONSORT statement was published in 2008, which provided a list of essential items to be included for reporting of abstracts of RCTs [9]. This statement comprises seventeen items distributed in eight sections which include: the title, authors contact details, trial design, methods (participants, interventions, objective, outcomes, randomization, blinding), results (numbers randomized, recruitment, numbers analyzed, outcome, harms), conclusions, trial registration and funding [9].

Following the publication of this CONSORT extension for abstract reporting, studies to assess the quality of abstract reporting in general medicine journals and other specific fields of medicine have been done. These studies have shown that there is substantial room for improvement in the adherence to these reporting guidelines [10-19].

However, as concerns RCTs in HIV/AIDS medicine, there are limited studies investigating the impact of CONSORT extension for abstract reporting checklist. In this field of HIV/AIDS where guidelines to tackle the pandemic are continually changing, adherence to this statement is particularly important, most especially as HIV/AIDS disproportionally affects resource limited settings (mainly sub-Saharan African countries) where most of the RCTs are done but most of health professionals do not have access to full-text articles required for health care decision making. We therefore, in the present study, using abstracts of the periods before and after the publication of CONSORT extension for abstracts, aim to first of all compare the overall reporting quality of RCTs in HIV/AIDS medicine published in general medicine and infectious diseases journals, and secondly determine the factors associated with better reporting quality.

\section{Methods \\ Design}

We conducted a systematic review of abstracts published in 2006, 2007, 2014 and 2015 in 20 leading general medicine and 20 leading infectious diseases journals based on 2014 impact factor.

\section{Data sources}

We conducted a MEDLINE/PubMed search of all RCTs published in the years 2006-2007 and 2014-2015. The search strategy used MeSH terms like "randomized controlled trial" as publication type, journal names and HIV and AIDS as terms in title/abstract. We limited search for the following periods: (2006/01/01 to 2007/12/31 and $2014 / 01 / 01$ to $2015 / 12 / 31$ ). The choice of the time limit of 2014 and 2015 was arbitrary and based on the fact that 6 years after the publication of the first CONSORT statement for abstracts in 2008, is sufficient time for researchers to have become versed with the recommendations. Other types of articles (editorial, case reports, comment, observational study, review, meta-analysis and letters) were excluded. Searches were done regularly during the study period and the last one was conducted on February 26, 2016 as could be seen presented in Additional file 1.

\section{Studies selection}

RCT abstracts where interventions were provided to HIV-infected patients were selected. These abstracts were included when participant allocation to interventions was described by the terms "random", "randomly allocated", "randomized", "randomization" or another word in the abstract suggesting that participants were randomly distributed between the trial arms. We considered journals as CONSORT statement endorser if they referenced CONSORT statement in their 'Instruction to authors/Submission guidelines' or if they reference as endorser in the CONSORT webpage (http://www.consortstatement.org/about-consort/consort-endorsement/consortendorsers-journals/). Two reviewers independently selected abstracts.

\section{Data extraction and covariates}

Data extraction was independently done by two reviewers using a pre-made and pretested data extraction form in compliance with the items of the recommendations of the evaluation of RCTs using the CONSORT for abstracts [9]. Each question had a 'yes' or 'no' response for each item 
indicating whether the authors had reported it or not. Agreement between the two reviewers was measured using the Kappa statistic [20] and discrepancies were resolved by discussion among the authors or by arbitration of a third author. Other information collected from journals other than the CONSORT abstracts items, were journal name, type of abstract format (IMRAD [introduction, method, results and discussion] or eightheading [objective, design, setting, participants, intervention, main outcome measure, results and conclusions] or one-block), type of interventions in the trial (pharmacological or non-pharmacological), number of authors, publication on behalf of a research collaboration group, and journal field (infectious diseases or general medicine).

\section{Main outcomes definition}

The primary outcome was the number of items reported in each selected abstract. The secondary one was the proportion of abstracts reporting each of 17 recommended items.

\section{Statistical analysis}

IBM Statistical Package for Social Science (IBM SPSS) version 23.0 for Windows (IBM Corp. Released 2014. IBM SPSS Statistics for Windows, Version 23.0. Armonk, NY: IBM Corp.) was used to code, enter and analyze data. Categorical variables were expressed as numbers with percentages (\%). Continuous variables were expressed as means with standard deviation.

We expressed the number of items for each year as mean (standard deviation [SD]). We estimated mean differences using the independent two-sample T-test for unadjusted means and the generalized estimation equations (GEEs) for adjusted means [21]. All these mean differences were reported with $95 \%$ confidence intervals (95\% CI). The $\chi^{2}$ was used to compare compliance with the 17 items of CONSORT extension for abstracts between pre-CONSORT and post-CONSORT for abstracts publication. This was also done using GEE for adjusted analysis. We reported measures of association as odd ratios (OR) for univariate analyses and as adjusted odds ratios (aOR) for multivariate analyses both with their $95 \% \mathrm{CI}$. A p-value $<0.05$ was considered statistically significant.

Incidence rate ratios (IRRs) were computed to identify factors associated with better reporting in 2014-15 abstracts using GEE. For this analysis, Poisson distribution and unstructured correlation matrix were assumed. Univariate and multivariate analyses were conducted.

For GEE, adjustments were made for CONSORT endorser journal (yes/no), abstract format (IMRAD/8-heading/ one-block), publication on behalf of a group (yes/no), number of authors $(\leq 6 / 7-12 / \geq 13)$, and journal field (general medicine/infectious diseases). Journal name has been used as grouping factor due to fact that they can similarity in articles published in the same journal. The adjustment was done for abstract format because there are previous studies reporting relationship between abstract format and quality reporting $[15,22]$. The adjustment was also done for number of authors and publication on behalf a group because it was reported an association with higher quality of work with number of collaborators [23, 24].

\section{Results \\ General characteristics of selected abstracts}

Our search yielded 444 articles of which 95 were published in 2006, 103 in 2007, 140 in 2014 and 106 in 2015. One hundred and thirty-two abstracts did not meet our inclusion criteria, hence were excluded. We therefore included 76 abstracts from 2006, 83 from 2007 (2006-07, $n=159), 81$ from 2014 and 72 from $2015(n=153)$ as shown in the flow diagram (Fig. 1).

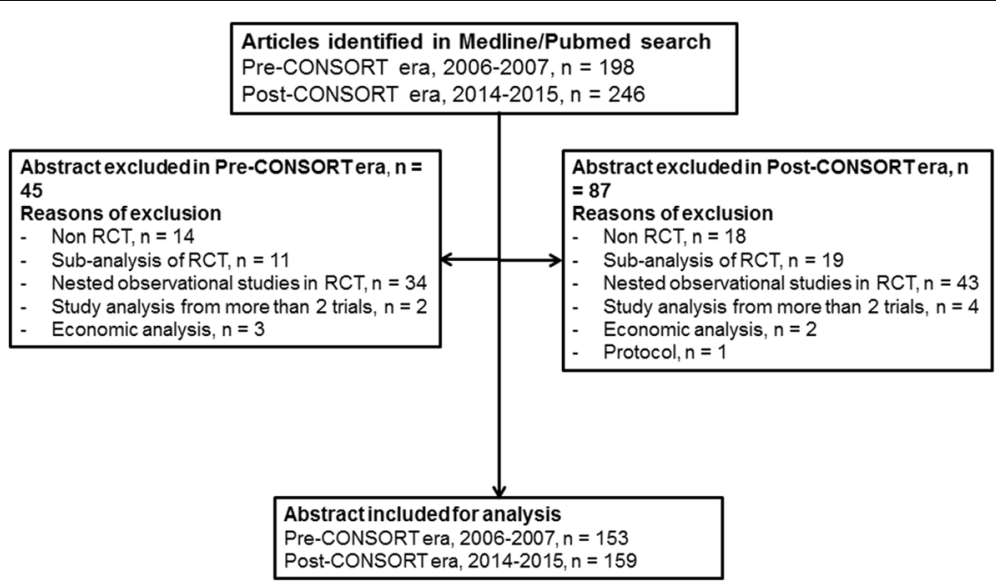

Fig. 1 Flow chart of included studies 
The inter-observer agreement value was 0.86 for abstract selection, 0.71 for overall rating of abstract reporting quality, and varied between 0.74 and 0.98 for each items of CONSORT for abstracts.

All articles came from 19 of 40 journals included in search strategy. Interventions were pharmacological/ vaccine in $76 \%(238 / 312)$ of the abstracts. The IMRAD format was used in $85 \%(266 / 312)$ of abstracts. Among all the journals, $84 \%$ of abstracts $(262 / 312)$ were from journals which endorsed CONSORT, $80 \%$ (248/312) were from infectious diseases journals, $63.5 \%(198 / 312)$ were published on behalf of a group, and $75 \%(233 / 312)$ were published in journals with impact factor less than 10 . The mean number of authors among articles was 12.2 (SD 6.8) (Table 1).

\section{Overall quality of reporting}

Only $1 \%(2 / 153)$ of abstracts reported all items in the 2014-15 period. The mean number of items reported in 2006-07 (6.2; SD = 2.5; Median 6; Range 1-14) differed significantly from that reported in 2014-15 (7.7; SD = 4.0; Median 7; Range 1-17), mean difference (MD): 1.6; $95 \%$ CI $0.8-2.3 ; \mathrm{p}<0.001$.

In the GEE analysis, after adjusting for covariates among the type of intervention, journal endorser of CONSORT, format of abstract, journal field, numbers of authors, journal impact factor and publication on a behalf of a group, the adjusted mean number of items reported in 2006-07 (7.2; $95 \%$ CI 6.6-7.7) differed significantly from that reported in 2014-15 (7.8; $95 \%$ CI 7.3-8.4), adjusted MD: $0.7 ; 95 \%$ CI $0.1-1.2 ; \mathrm{p}=0.015$.

\section{Quality of reporting of each item}

In univariate analysis, there was improvement from 2006-07 to 2014-15 for 'title, 'trial design', 'participants', 'objective,' 'randomization', 'blinding,' 'recruitment,' 'number analyzed,' 'outcome,' 'conclusion,' 'trial registration' and 'funding'. However, the quality of abstracts decreased for 'author contact'. After adjustment, the quality of abstract remained improved for the following items: 'participants' (aOR 1.92; 95 \% CI 1.05-3.51), 'randomization' ( $\mathrm{p}<0.001$ ), 'outcome' of results section (aOR 2.26; 95 \% CI 1.174.35), 'trial registration' (aOR 8.32; 95 \% CI 3.66-10.88) and 'funding' $(\mathrm{p}<0.001)$. From the $2006-07$ period to the 2014-15 period, the quality of the item 'author contact' decreased (aOR 0.06; 95 \% CI 0.03-0.12) (Table 2).

\section{Factors associated with better reporting quality in 2014-2015 abstracts}

In univariate analysis, factors associated with better reporting included publishing in general medicine journal, publishing in CONSORT endorser journals, structured abstract (IMRAD or 8-heading), high impact journal, more than 13 authors and publishing on behalf of a research collaboration group. In multivariate analysis, factors independently associated with better reporting of abstracts in 2014-15 included publishing on nonpharmacological/vaccine intervention (aIRR 1.19; $95 \%$ CI 1.03-1.37), more than 13 authors (aIRR 1.39; $95 \%$ CI 1.07-1.79) and high journal impact factor (aIRR 2.16; $95 \%$ CI 1.83-2.54) (Table 3).

\section{Discussion}

This study aimed to assess, according to the CONSORT for abstract checklist, the differences in the reporting quality of abstracts of RCTs in HIV/AIDS medicine published in general medicine and infectious diseases journals before (in the years 2006-07) and after (in the years 2014-15) the publication of the CONSORT extension for abstracts [9]. Our findings demonstrate that for some items (participants, randomization, outcome of results section, trial registration and funding), the reporting quality of HIV/AIDS RCT abstracts has improved significantly in the post-CONSORT era as compared to the preCONSORT era, while for others the quality has remained unchanged or regressed (authors contact). These results are consistent with previous studies that have reported inconsistencies and patterns of non-compliance to the CONSORT for abstracts guidelines in most of journals [10-19].

The mean number of items reported increased significantly from $2006-07$ to $2014-15$. This is in line with the average of 3 more items reported in RCT abstracts in top-tiers of general medicine journals since 2008 as found in a recent study [19]. High impact factor was independently associated with more adherence to CONSORT abstract items as in a study in which high impact factor is associated with high quality reporting for CONSORT items [15, 25-30]. Many people and institutions consider journal impact factor as the reflect of articles' quality [31]. High number of authors was also independently associated with more adherence to CONSORT abstract items as in previous studies [23, 24]. One can argue that the involvement of a large number of authors in an article could improve quality. Many authors would increase the chances that one or more of the authors ensure to the respect of the reporting guidelines. We also found non pharmacological/vaccine intervention in trial a factor for better reporting. This finding requires more investigation to understand this relationship.

As a whole, the reporting of some items improved significantly over time: more abstracts in $2014-15$ as compared to 2006-07 identified the study as randomized in the title, provided details on the trial design, randomization, blinding, trial registration and funding. For most abstract elements there was progress in reporting even though this was not significant. One of the main reasons that can explain the improvement of the overall 
Table 1 Distribution of HIV abstracts by year and characteristics

\begin{tabular}{|c|c|c|c|}
\hline & $\begin{array}{l}2006-2007 \\
n=159\end{array}$ & $\begin{array}{l}2014-2015 \\
n=153\end{array}$ & $\begin{array}{l}\text { All } \\
N=312\end{array}$ \\
\hline \multicolumn{4}{|l|}{ Journals } \\
\hline - AIDS & $50(31.4)$ & $20(13.1)$ & $70(22.4)$ \\
\hline - AIDS Patient Care STDS & $2(1.3)$ & $7(4.6)$ & $9(2.9)$ \\
\hline - Annals of Internal Medicine & $2(1.3)$ & $2(1.3)$ & $4(1.3)$ \\
\hline - Archives of Internal Medicine & $4(2.5)$ & 0 & $4(1.3)$ \\
\hline - BMC Medicine & 0 & $3(2.0)$ & $3(1.0)$ \\
\hline - British Medical Journal & $3(1.9)$ & $2(1.3)$ & $5(1.6)$ \\
\hline - Clinical Infectious Diseases & $12(7.5)$ & $8(5.2)$ & $20(6.4)$ \\
\hline - HIV Medicine & $8(5.0)$ & $4(2.6)$ & $12(3.8)$ \\
\hline $\begin{array}{l}\text { - International Journal of } \\
\text { Antimicrobial Agents }\end{array}$ & 0 & $1(0.7)$ & $1(0.3)$ \\
\hline - JAMA Internal Medicine & 0 & $1(0.3)$ & $1(0.3)$ \\
\hline $\begin{array}{l}\text { - Journal of Acquire Immune } \\
\text { Deficiency Syndrome }\end{array}$ & $39(24.5)$ & $40(26.1)$ & 79 (25.3) \\
\hline $\begin{array}{l}\text { - Journal of Antimicrobial } \\
\text { Chemotherapy }\end{array}$ & $1(0.6)$ & $3(2.0)$ & $4(1.3)$ \\
\hline - Journal of Infectious Diseases & $14(8.8)$ & $10(6.5)$ & $24(7.7)$ \\
\hline $\begin{array}{l}\text { - Journal of the American } \\
\text { Medical Association, The }\end{array}$ & $2(1.3)$ & $6(3.9)$ & $9(2.9)$ \\
\hline $\begin{array}{l}\text { - Journal of the International } \\
\text { AIDS Society }\end{array}$ & 0 & $3(2.0)$ & $3(1.0)$ \\
\hline $\begin{array}{l}\text { - Lancet Infectious Diseases, } \\
\text { The }\end{array}$ & 0 & $20(13.1)$ & $20(6.4)$ \\
\hline - Lancet, The & $14(8.8)$ & $7(4.6)$ & $21(6.7)$ \\
\hline $\begin{array}{l}\text { - New England Journal of } \\
\text { Medicine, The }\end{array}$ & $6(3.8)$ & $7(4.6)$ & $13(4.2)$ \\
\hline $\begin{array}{l}\text { - Pediatric Infectious Diseases } \\
\text { Journal, The }\end{array}$ & 0 & $6(3.9)$ & $6(1.9)$ \\
\hline - PLoS Medicine & $2(1.3)$ & $3(2.0)$ & $5(1.6)$ \\
\hline Mean number of authors & $11.1(4.6)$ & $13.3(8.4)$ & $12.2(6.8)$ \\
\hline$-0-6$ & $19(12.0)$ & $20(13.1)$ & $39(12.5)$ \\
\hline$-7-12$ & $97(61.0)$ & $67(43.8)$ & $164(52.6)$ \\
\hline - 13 and more & $43(27.0)$ & $66(43.1)$ & $109(34.9)$ \\
\hline \multicolumn{4}{|l|}{ Journal impact factor } \\
\hline$-<10$ & $126(79.2)$ & $107(69.9)$ & $233(74.7)$ \\
\hline$-\geq 10$ & $33(20.8)$ & $46(30.1)$ & $79(25.3)$ \\
\hline \multicolumn{4}{|c|}{ Pharmacological/Vaccine intervention } \\
\hline - Yes & $129(81.1)$ & $109(71.2)$ & $238(76.3)$ \\
\hline - No & $30(18.9)$ & $44(28.8)$ & $74(23.7)$ \\
\hline \multicolumn{4}{|l|}{ Abstract format } \\
\hline - IMRAD & $137(86.2)$ & $129(84.3)$ & $266(85.3)$ \\
\hline - Eight-heading & $11(6.9)$ & $14(9.2)$ & $25(8.0)$ \\
\hline - One-block & $11(6.9)$ & $10(6.5)$ & $21(6.7)$ \\
\hline \multicolumn{4}{|l|}{ CONSORT Endorsers journals } \\
\hline - Yes & $137(86.2)$ & $125(81.7)$ & $262(84.0)$ \\
\hline - No & $22(13.8)$ & $28(18.3)$ & $50(16.0)$ \\
\hline
\end{tabular}

Table 1 Distribution of HIV abstracts by year and characteristics (Continued)

Journal field

- Infectious diseases $\quad 126(79.2) \quad 122(79.7) \quad 248(79.5)$

- General medicine $\quad 33(20.8) \quad 31(20.3) \quad 64(20.5)$

Publication on behalf of a group

- Yes $\quad 97(61.0) \quad 52(34.0) \quad 114(36.5)$

$\begin{array}{llll}\text { - No } & 62(39.0) & 101(66.0) & 198(63.5)\end{array}$

There were no abstract for the following journals included in search strategy: AIDS Review, The American Journal of Medicine, American Journal of Preventive Medicine, Annals of Family Medicine, Annals of Medicine, Canadian Medical Association Journal, Clinical Microbiology and Infection, Cochrane Database of Systematic Reviews, Current Opinion in HIV and AIDS, Current Opinion in Infectious Diseases, Emerging Infectious Diseases journal, Eurosurveillance, Infection and Immunity, Infection Control and Hospital Epidemiology, Journal of Cachexia Sarcopenia Muscle, Journal of infection, Journal of Internal Medicine, Mayo Clinic Proceedings, Medicine and Translational Research

reporting quality of abstracts found in our study is the endorsement of the CONSORT statement by most of the journals surveyed. Indeed, $84 \%$ of articles included in our analysis were published in journals that endorsed CONSORT. A systematic review that examined the effectiveness of the CONSORT statement in journals that have formally endorsed it concluded that journals' adoption of CONSORT is associated with improved reporting of RCTs [8]. Moreover, another study has also shown that the endorsement of recommendation and effective implementation of CONSORT guidelines lead to the improvement of reporting quality of abstracts [12]. In line with these studies, our findings stress the need to expand journal endorsement and implementation of the CONSORT extension for abstracts before manuscript submission (in journal submission guidelines), during review process and editorial assessment. Authors should be required to submit a completed CONSORT checklist with each manuscript with an emphasis for CONSORT extension for abstracts [32]; reviewers should assess the completeness of abstract reporting; and final manuscript copyediting would surely improve abstract reporting quality [19].

Despite this overall improvement, the quality of reporting of some items remained sub-optimal, consistent with findings from other studies [10-19]. Poorly reported items specifically include methods of randomization and allocation concealment, and blinding. These items are essential methodological elements which are critical, therefore adequate standardized reporting is indispensable so as to demonstrate that selection bias was avoided, thereby allowing unequivocal interpretations of the study findings [5]. Nevertheless, less abstracts in 2014-15 reported corresponding authors' details (postal and email addresses). This is a major drawback when readers need to contact authors for further information on the study. This depends on journal indexing policy, rather than a deficiency 
Table 2 Crude and adjusted odds ratios for adherence to the 12 items of the CONSORT statement for HIV/AIDS abstracts in 2014-2015 compared to 2006-2007

\begin{tabular}{|c|c|c|c|c|c|c|c|}
\hline \multirow[t]{3}{*}{ Item } & \multirow[t]{3}{*}{ Criteria } & \multicolumn{2}{|c|}{ Items reported, $n$ (\%) } & \multicolumn{4}{|c|}{ Data collection period (2014-15 versus 2006-07) } \\
\hline & & \multirow{2}{*}{$\begin{array}{l}2014-15 \\
n=153\end{array}$} & \multirow{2}{*}{$\begin{array}{l}2006-07 \\
n=159\end{array}$} & \multicolumn{2}{|l|}{ Univariate analysis $^{\mathrm{a}}$} & \multicolumn{2}{|l|}{ Multivariate analysis $^{\mathrm{b}}$} \\
\hline & & & & Odds ratio $(95 \% \mathrm{Cl})$ & $P$ & Adjusted odds ratio $(95 \% \mathrm{Cl})$ & $P$ \\
\hline Title & Identification of the study as randomized & $103(67.3)$ & $80(50.3)$ & $2.03(1.30-3.22)$ & .002 & $1.57(0.93-2.65)$ & .090 \\
\hline Author contact & $\begin{array}{l}\text { Contact details for the corresponding author including both postal } \\
\text { and email addresses }\end{array}$ & $28(18.3)$ & $110(69.2)$ & $0.10(0.06-0.17)$ & $<.001$ & $0.06(0.03-0.12)$ & $<.001$ \\
\hline Trial design & $\begin{array}{l}\text { Description of the trial design (eg, parallel, cluster, non-inferiority, } \\
\text { parallel, N-of-1 trial, etc.) }\end{array}$ & $45(29.4)$ & $29(18.2)$ & $1.87(1.10-3.18)$ & .020 & $1.56(0.86-2.83)$ & .142 \\
\hline \multicolumn{8}{|l|}{ Methods } \\
\hline - Participants & $\begin{array}{l}\text { Eligibility criteria for participants and the settings where the data } \\
\text { were collected }\end{array}$ & $73(47.7)$ & $45(28.3)$ & $2.31(1.45-3.69)$ & $<.001$ & $1.92(1.05-3.51)$ & .034 \\
\hline - Interventions & Interventions intended for each group & $142(92.8)$ & $140(88.1)$ & $1.75(0.80-3.82)$ & .154 & $2.26(0.99-5.12)$ & .052 \\
\hline - Objective & Specific objective or hypothesis & $126(82.4)$ & $115(72.3)$ & $1.79(1.04-3.07)$ & .035 & $1.31(0.72-2.39)$ & .384 \\
\hline - Outcome & Clearly defined primary outcome & $70(45.8)$ & $74(46.5)$ & $0.97(0.62-1.51)$ & .889 & $0.69(0.39-1.22)$ & .200 \\
\hline - Randomization & How participants were allocated to interventions & $19(12.4)$ & 0 & Not estimable & $<.001$ & Not estimable & $<.001$ \\
\hline - Blinding (masking) & $\begin{array}{l}\text { Whether or not participants, care givers and those assessing the } \\
\text { outcomes were blinded to group assignment }\end{array}$ & $18(11.8)$ & $3(1.9)$ & $6.93(2.00-24.05)$ & $<.001$ & $4.10(0.81-20.46)$ & .087 \\
\hline \multicolumn{8}{|l|}{ Results } \\
\hline - Number randomized & Number of participants randomized to each group & $64(41.8)$ & $56(35.2)$ & $1.32(0.84-2.09)$ & .230 & $1.15(0.69-1.91)$ & .601 \\
\hline - Recruitment & Trial status & $50(32.7)$ & $31(19.5)$ & $2.00(1.19-3.36)$ & .008 & $1.48(0.82-2.68)$ & .192 \\
\hline - Number analyzed & Number of participants analyzed in each group & $65(42.5)$ & $40(25.2)$ & $2.20(1.36-3.55)$ & .001 & $1.69(0.94-3.04)$ & .077 \\
\hline - Outcome & $\begin{array}{l}\text { For the primary outcome, a result for each group and the estimated } \\
\text { effect size and its precision }\end{array}$ & $65(42.5)$ & $40(25.2)$ & $2.20(1.36-3.55)$ & .001 & $2.26(1.17-4.35)$ & .015 \\
\hline - Harms & Important adverse events or side-effects & $78(51.0)$ & $75(47.2)$ & $1.16(0.75-1.82)$ & .501 & $1.15(0.65-2.02)$ & 632 \\
\hline Conclusions & General interpretation of the results & $118(77.1)$ & $102(64.2)$ & $1.88(1.15-3.10)$ & .012 & $1.59(0.92-2.74)$ & .094 \\
\hline Trial registration & Registration number and name of trial register & $84(54.9)$ & $38(23.9)$ & $3.88(2.39-6.29)$ & $<.001$ & $8.32(3.66-10.88)$ & $<.001$ \\
\hline Funding & Source of funding & $34(22.2)$ & $1(0.6)$ & $45.14(6.09-334.48)$ & $<.001$ & Not estimable & $<.001$ \\
\hline
\end{tabular}


Table 3 Unadjusted and adjusted incidence rate ratios for the total number of CONSORT extension for HIV abstract items reported

\begin{tabular}{|c|c|c|c|c|}
\hline \multirow[t]{3}{*}{ Variables } & \multicolumn{4}{|l|}{ Total number of items reported } \\
\hline & \multicolumn{2}{|l|}{ Univariate analysis } & \multicolumn{2}{|l|}{ Multivariate analysis } \\
\hline & Incidence rate ratio (95 \% Cl) & $p$ & Adjusted incidence rate ratio $(95 \% \mathrm{Cl})$ & $p$ \\
\hline \multicolumn{5}{|l|}{ Journal field } \\
\hline - General medicine & $33.11(9.72-112.73)$ & $<.001$ & $1.19(1.00-1.41)$ & .052 \\
\hline - Infectious diseases & & & 1 & \\
\hline \multicolumn{5}{|l|}{ CONSORT endorsement } \\
\hline - Non endorser journals & & & 1 & \\
\hline - Endorser journals & $11.22(3.90-32.27)$ & $<.001$ & $1.01(0.85-1.21)$ & .900 \\
\hline \multicolumn{5}{|l|}{ Abstract format } \\
\hline - One-block & & & 1 & \\
\hline - IMRAD & $20.69(6.94-61.61)$ & $<.001$ & $1.11(0.81-1.51)$ & .524 \\
\hline - Eight-heading & $57.81(14.64-228.23)$ & $<.001$ & $1.28(1.00-1.67)$ & .061 \\
\hline \multicolumn{5}{|c|}{ Pharmacological/Naccine intervention } \\
\hline - Yes & & & 1 & \\
\hline - No & $0.40(0.11-1.42)$ & .155 & $1.19(1.03-1.37)$ & .015 \\
\hline \multicolumn{5}{|l|}{ Journal impact factor } \\
\hline$-<10$ & & & 1 & \\
\hline$-\geq 10$ & $511.06(186.40-1401.21)$ & $<.001$ & $2.16(1.83-2.54)$ & $<.001$ \\
\hline \multicolumn{5}{|l|}{ Number of authors } \\
\hline - Less than 6 & & & 1 & \\
\hline$-7-12$ & $3.81(0.75-19.41)$ & .108 & $1.18(0.98-1.48)$ & .140 \\
\hline - More than 13 & $89.74(15.30-526.36)$ & $<.001$ & $1.39(1.07-1.79)$ & .013 \\
\hline \multicolumn{5}{|c|}{ Publication on behalf of a collaboration research group } \\
\hline - No & & & 1 & \\
\hline - Yes & $13.09(3.50-48.97)$ & $<.001$ & $0.99(0.88-1.11)$ & .867 \\
\hline
\end{tabular}

Cl confidence interval, CONSORT consolidated standards of reporting trials, IMRAD introduction, methods, results and discussion

in reporting. In addition, author contact details are more relevant for conference abstracts, none of which were included in this study [5].

Though we found that there has been some improvement in HIV RCT abstract reporting, our study had some limitations. We not investigated others factors that can influence reporting quality. These non-investigated factors include abstract word count, types of utilization of CONSORT guidelines in the 'instructions for authors' section of journals, and awareness of the CONSORT statement. Furthermore, this study reports on the adequacy of reporting using the CONSORT checklist items, but the accuracy of reporting cannot be assured because a comparison of the abstract and the full text was beyond our scope.

\section{Conclusions}

The reporting quality of RCT abstracts in HIV/AIDS medicine in general medicine and infectious diseases journals has sub-optimally improved after the publication of the CONSORT extension for abstracts. This suboptimal improvement is associated with journal high impact factor, high number of authors and non-pharmacological/vaccine intervention in the trial. However, there is still much to do for improvement to meet the standards of the CONSORT for abstracts guidelines. Journal endorsement and more strict adherence to the CONSORT for abstracts standards by both authors and journal editors will contribute to better RCT reports in HIV/AIDS medicine. Further researches are necessary to investigate why authors, reviewers, journal editors, funders, institutions and readers not fully adhere to CONSORT guidelines.

\section{Additional file}

Additional file 1: Search strategy for HIV RCTs published in 2006-2007 and 2014-2015 in leading general medicine and infectious diseases journals. (DOCX $14 \mathrm{~kb})$

\section{Abbreviations}

(a)OR: (adjusted) odds ratio; AIDS: Acquired immunodeficiency syndrome; $\mathrm{Cl}$ : Confidence interval; CONSORT: Consolidated standards of reporting trials; GEE: Generalized estimation equations; HIV: Human immunodeficiency virus; 
IMRAD: Introduction, method, results and discussion; IRR: Incidence rate ratio; RCT: Randomized controlled trials; SD: Standard deviation

\section{Acknowledgements}

None to declare.

\section{Funding}

This research did not receive any specific grant from funding agencies in the public, commercial or not-for-profit sectors.

\section{Availability of data and materials}

The datasets during and/or analyzed during the current study available from the corresponding author on reasonable request.

\section{Authors' contributions}

Study conception and design: JJRB and JJNN. Data collection: JJRB. Abstract selection: LNU, PSDS and JJRB. Data extraction: LNU, PSDS and JJRB. Statistical analysis: JJRB. Data interpretation: JJRB, JJNN, SLA, ET and MCT. Drafting: JJRB and JJNN. Critical discussion and manuscript revision: All authors. Approved the final version of the manuscript: All authors.

\section{Competing interests}

The authors declare that they have no competing interests.

\section{Consent for publication}

Not applicable.

\section{Ethics approval and consent to participate}

Not applicable.

\section{Author details}

'Department of Epidemiology and Public Health, Centre Pasteur of Cameroon, Member of the International Network of the Pasteur Institute, Yaoundé, Cameroon. 'Department of Medicine, Groote Schuur Hospital and University of Cape Town, Cape Town, South Africa. ${ }^{3}$ Medical Diagnostic Center, Yaoundé, Cameroon. ${ }^{4}$ Faculty of Medicine and Biomedical Sciences, University of Yaoundé 1, Yaoundé, Cameroon. ${ }^{5}$ Internal Medicine Unit, Douala General Hospital, Douala, Cameroon. ${ }^{6}$ Molecular Mycology Unit, Institut Pasteur of Paris, Paris, France.

\section{Received: 23 July 2016 Accepted: 8 October 2016}

\section{Published online: 13 October 2016}

\section{References}

1. Concato J, Shah N, Horwitz RI. Randomized, controlled trials, observational studies, and the hierarchy of research designs. N Engl J Med. 2000;342(25):1887-92.

2. Stolberg HO, Norman G, Trop I. Randomized controlled trials. AJR Am J Roentgenol. 2004;183(6):1539-44.

3. The impact of open access upon public health. PLoS Med. 2006;3(5):e252.

4. Smith H, Bukirwa H, Mukasa O, Snell P, Adeh-Nsoh S, Mbuyita S, Honorati M, Orji B, Garner P. Access to electronic health knowledge in five countries in Africa: a descriptive study. BMC Health Serv Res. 2007;7:72.

5. Hopewell S, Clarke M, Moher D, Wager E, Middleton P, Altman DG, Schulz KF. CONSORT for reporting randomized controlled trials in journal and conference abstracts: explanation and elaboration. PLoS Med. 2008;5(1):e20

6. Begg C, Cho M, Eastwood S, Horton R, Moher D, Olkin I, Pitkin R, Rennie D, Schulz KF, Simel D, et al. Improving the quality of reporting of randomized controlled trials. The CONSORT statement. JAMA. 1996;276(8):637-9.

7. Moher D, Schulz KF, Altman DG. The CONSORT statement: revised recommendations for improving the quality of reports of parallel-group randomized trials. J Am Podiatr Med Assoc. 2001;91(8):437-42.

8. Plint AC, Moher D, Morrison A, Schulz K, Altman DG, Hill C, Gaboury I. Does the CONSORT checklist improve the quality of reports of randomised controlled trials? A systematic review. Med J Aust. 2006;185(5):263-7.

9. Hopewell S, Clarke M, Moher D, Wager E, Middleton P, Altman DG, Schulz KF. CONSORT for reporting randomised trials in journal and conference abstracts. Lancet. 2008:371(9609):281-3.

10. Can OS, Yilmaz AA, Hasdogan M, Alkaya F, Turhan SC, Can MF, Alanoglu Z. Has the quality of abstracts for randomised controlled trials improved since the release of Consolidated Standards of Reporting Trial guideline for abstract reporting? A survey of four high-profile anaesthesia journals. Eur Anaesthesiol. 2011:28(7):485-92.

11. Samaan Z, Mbuagbaw L, Kosa D, Borg Debono V, Dillenburg R, Zhang S, Fruci $V$, Dennis B, Bawor M, Thabane L. A systematic scoping review of adherence to reporting guidelines in health care literature. J Multidiscip Healthc. 2013:6:169-88.

12. Hopewell S, Ravaud P, Baron G, Boutron I. Effect of editors' implementation of CONSORT guidelines on the reporting of abstracts in high impact medical journals: interrupted time series analysis. BMJ. 2012;344:e4178.

13. Fleming PS, Buckley N, Seehra J, Polychronopoulou A, Pandis N. Reporting quality of abstracts of randomized controlled trials published in leading orthodontic journals from 2006 to. Am J Orthod Dentofac Orthop. 2011:142(4):451-8.

14. Knobloch K, Vogt PM. Adherence to CONSORT abstract reporting suggestions in surgical randomized-controlled trials published in Annals of Surgery. Ann Surg. 2011;254(3):546. author reply 546-547.

15. Ghimire S, Kyung E, Lee H, Kim E. Oncology trial abstracts showed suboptimal improvement in reporting: a comparative before-and-after evaluation using CONSORT for Abstract guidelines. J Clin Epidemiol. 2014:67(6):658-66.

16. Seehra J, Wright NS, Polychronopoulou A, Cobourne MT, Pandis N. Reporting quality of abstracts of randomized controlled trials published in dental specialty journals. J Evid Based Dent Pract. 2013;13(1):1-8.

17. Chen Y, Li J, Ai C, Duan Y, Wang L, Zhang M, Hopewell S. Assessment of the quality of reporting in abstracts of randomized controlled trials published in five leading Chinese medical journals. PLoS One. 2010:5(8):e11926.

18. Ghimire S, Kyung E, Kang W, Kim E. Assessment of adherence to the CONSORT statement for quality of reports on randomized controlled trial abstracts from four high-impact general medical journals. Trials. 2012;13:77.

19. Mbuagbaw L, Thabane M, Vanniyasingam T, Borg Debono V, Kosa S, Zhang S, Ye C, Parpia S, Dennis BB, Thabane L. Improvement in the quality of abstracts in major clinical journals since CONSORT extension for abstracts: a systematic review. Contemp Clin Trials. 2014:38(2):245-50.

20. Viera AJ, Garrett JM. Understanding interobserver agreement: the kappa statistic. Fam Med. 2005:37(5):360-3.

21. Hanley JA, Negassa A, Edwardes MD, Forrester JE. Statistical analysis of correlated data using generalized estimating equations: an orientation. Am J Epidemiol. 2003;157(4):364-75.

22. Dupuy A, Khosrotehrani K, Lebbe C, Rybojad M, Morel P. Quality of abstracts in 3 clinical dermatology journals. Arch Dermatol. 2003;139(5):589-93.

23. Figg WD, Dunn L, Liewehr DJ, Steinberg SM, Thurman PW, Barrett JC, Birkinshaw J. Scientific collaboration results in higher citation rates of published articles. Pharmacotherapy. 2006;26(6):759-67.

24. Willis DL, Bahler CD, Neuberger MM, Dahm P. Predictors of citations in the urological literature. BJU Int. 2011;107(12):1876-80.

25. Lee SY, Teoh PJ, Camm CF, Agha RA. Compliance of randomized controlled trials in trauma surgery with the CONSORT statement. J Trauma Acute Care Surg. 2013;75(4):562-72

26. Camm CF, Chen Y, Sunderland N, Nagendran M, Maruthappu M, Camm AJ. An assessment of the reporting quality of randomised controlled trials relating to anti-arrhythmic agents (2002-2011). Int J Cardiol. 2013;168(2):1393-6.

27. Lai R, Chu R, Fraumeni M, Thabane L. Quality of randomized controlled trials reporting in the primary treatment of brain tumors. J Clin Oncol. 2006;24(7):1136-44

28. Toulmonde M, Bellera C, Mathoulin-Pelissier S, Debled M, Bui B, Italiano A. Quality of randomized controlled trials reporting in the treatment of sarcomas. J Clin Oncol. 2011:29(9):1204-9.

29. Peron J, Pond GR, Gan HK, Chen EX, Almufti R, Maillet D, You B. Quality of reporting of modern randomized controlled trials in medical oncology: a systematic review. J Natl Cancer Inst. 2012;104(13):982-9.

30. Mills E, Wu P, Gagnier J, Heels-Ansdell D, Montori VM. An analysis of general medical and specialist journals that endorse CONSORT found that reporting was not enforced consistently. J Clin Epidemiol. 2005;58(7):662-7.

31. Saha S, Saint S, Christakis DA. Impact factor: a valid measure of journal quality? J Med Libr Assoc. 2003;91(1):42-6.

32. Rios LP, Odueyungbo A, Moitri MO, Rahman MO, Thabane L. Quality of reporting of randomized controlled trials in general endocrinology literature. J Clin Endocrinol Metab. 2008:93(10):3810-6. 